\title{
A FOTOGRAFIA DE NATUREZA COMO INSTRUMENTO PARA EDUCAÇÃO AMBIENTAL
}

\author{
Nature photography as an instrument \\ in Environmental Education
}

\author{
Marilia Dammski Borges ${ }^{1}$ \\ José Marcelo Aranha ${ }^{2}$ \\ José Sabino ${ }^{3}$
}

\begin{abstract}
Resumo: A visão é um dos sentidos mais importantes nos humanos e, por isso, a fotografia pode ser uma excelente opção para driblar a falta de recursos na educação ambiental, sensibilizando e ensinando por meio de sua informação e beleza. Partindo disso, este trabalho destina-se a estabelecer como a fotografia da natureza instrumentaliza a educação ambiental e contribui no aprendizado de alunos do Ensino Fundamental e Educação de Jovens e Adultos (EJA). Foram ministradas palestras em metade das turmas escolhidas utilizando fotografias e, em outra metade, sem este recurso. Para testar o aprendizado foram aplicados questionários avaliativos. Nas turmas onde foram utilizadas fotografias, houve aumento significativo nas respostas corretas. Analisando os resultados, concluiu-se que a fotografia da natureza pode ser utilizada com eficácia para diversas faixas etárias e diferentes níveis de ensino como instrumento para a educação ambiental
\end{abstract}

Palavras-chave: Fotografia. Natureza. Educação ambiental.

Abstract: Vision is one of the most important senses in humans and because of this the photographs are an excellent option to improve the lack of resources in Environmental Education. Photographs are a way of sensitizing and teaching the information and beauty of its components. The present article wants to establish how photographs of nature can give support to Middle School and Youths and Adults Education (EJA). Using Nature photography, presentations were made to half of the groups. The other half did not use the photographic resources. In order to test their knowledge, evaluative questionnaires were applied. At the groups that the photographs were used, there were a higher number of correct answers. Analyzing the results, it is possible to conclude that Nature photography can efficiently be used with different ages and also different levels of students as an instrument in the Environmental Education.

Keywords: Photography. Nature. Environmental education.

${ }^{1}$ Licenciada em Ciências Biológicas. Especialista em Educação Ambiental. Professora, Município de Itapema, SC, Brasil.<mariliaborges@yahoo.com.br>

${ }^{2}$ Biólogo. Doutor em Ecologia e Recursos Naturais. Docente, Departamento de Zoologia, Diretor do setor de Ciências Biológicas, Universidade Federal do Paraná (UFPR). Curitiba, PR, Brasil.<jmaranha@ufpr.br>

${ }^{3}$ Biólogo. Doutor em Ecologia. Docente, Programa de Meio Ambiente e Desenvolvimento Regional, Universidade Anhanguera - Uniderp. Campo Grande, MS, Brasil. Bolsista de produtividade CNPq.

<jose.sabino@pq.cnpq.br>

${ }^{1}$ Rua Curió, 245

Bairro de Bombas - Bombinhas, SC

$88.215-000$

149

Ciência $\mathfrak{E}^{2}$ Educação, v. 16, n. 1, p. 149-161, 2010 
Borges, M. D.; Aranha, J. M.; Sabino, J.

\section{Introdução}

A visão é um dos sentidos mais importantes nos humanos. Para Berne e Levy, (1998) a visão evoluiu como sentido dominante nos primatas, o que levou a espécie humana a depender da visão para a comunicação. Douglas (2000) afirma que, dentro dos sistemas sensoriais da espécie humana, a visão é um dos sentidos mais evoluídos, permitindo conhecer o mundo externo, pela formação de imagens em um receptor específico localizado na retina. Então, o cérebro recebe impulsos elétricos gerados na retina e interpreta as imagens ópticas determinando a sensação visual propriamente dita.

Douglas (2000) descreve detalhadamente o aspecto funcional da visão na espécie humana. Na sensação da geração visual deve haver um estímulo luminoso, representado por uma faixa estrita de espectro eletromagnético, constituindo o espectro de luz visível para o homem. O sistema que recebe a onda luminosa é representado pelo olho que cumpre as funções de transmissão (humor aquoso, vítreo e cristalino) e transdução (receptores) da luz. Os receptores são cones e bastonetes que têm pigmentos fotossensíveis. A captação da luz pelos movimentos provoca mudanças elétricas por movimentação de sódio na membrana. Reações subsequentes, com participação de uma proteína $\mathrm{G}$, fazem com que os potenciais de ação, formados em células específicas (bipolares e ganglionares), sejam transmitidos pelas vias ópticas até o córtex visual do lobo occipital, onde são formadas as imagens com as cores correspondentes. A função ocular é facilitada por reflexos de acomodação do cristalino, diâmetro pupilar e da convergência do globo ocular (DOUGLAS, 2000).

A educação ambiental pode ser vista como uma forma de intervenção na problemática ambiental, mediadora de programas educativos que começam antes e vão além da escola formal. A prática da educação ambiental já é regulamentada no Brasil pela Lei 9.795/1999 (BRASIL, 1999) que diz em seus artigos primeiro e segundo:

Art $1^{\circ}$. Entende-se por Educação Ambiental os processos pelo meio dos quais o indivíduo e a coletividade constroem valores sociais, conhecimentos, habilidades, atitudes e competências voltadas para a conservação do Meio Ambiente, bem do uso comum do povo, essencial à sadia qualidade de vida e sua sustentabilidade.

Art $2^{\circ}$. A Educação Ambiental é um componente essencial e permanente da educação nacional, devendo estar presente, de forma articulada, em todos os níveis e modalidades do processo educativo em caráter formal e não formal.

No entanto, a educação ambiental sofre com a falta de recursos (materiais e etc.) para que esta se faça efetivamente presente nas escolas. A fotografia é uma excelente opção, pois vem sensibilizar, com a beleza de seus componentes, e ensinar por meio das informações contidas nela ou que podemos extrair do seu conteúdo. Segundo Sauvé (2005), tendo em vista a amplitude da educação ambiental, bem como dela se exigir mudanças em profundidade, esta forma de educação é certamente de difícil realização.

A fotografia é um instrumento de grande importância pedagógica e muitas vezes essencial para diversas áreas de ensino. Ela, como linguagem não-verbal também contribui 
decisivamente na realização de pesquisas teóricas, manifestações artístico-culturais e como coadjuvante eficaz em inúmeras descobertas científico-tecnológicas (SPENCER, 1980). A fotografia contribui para a ciência, pois representa uma sequência qualificada de informação que não pode ser obtida de nenhuma outra forma, e também nos dota de uma espécie de olho sintético - "uma retina imparcial e infalível" - capaz de converter, em registros visíveis, fenômenos cuja existência, de outra forma, não haveríamos conhecido nem suspeitado (SPENCER, 1980).

As fotografias da natureza sensibilizam e provocam curiosidade pelo que compõe a imagem. Como um exemplo, a fotografia de um corrupião segurando uma pena em uma das patas (Figura 1).

Comumente esta fotografia provoca curiosidade, instigando ao observador o porquê de o pássaro estar com essa pena e, a partir disso, outras informações são pedidas, como o local onde vive, do que ele se alimenta etc. Desta forma, o efeito desejado foi alcançado, que seria o de sensibilizar e provocar curiosidade. A partir daí podem-se inserir diversas informações como, por exemplo, discorrer sobre a destruição do seu habitat.

Outra imagem e bom exemplo é a de um morango (Figura 2).

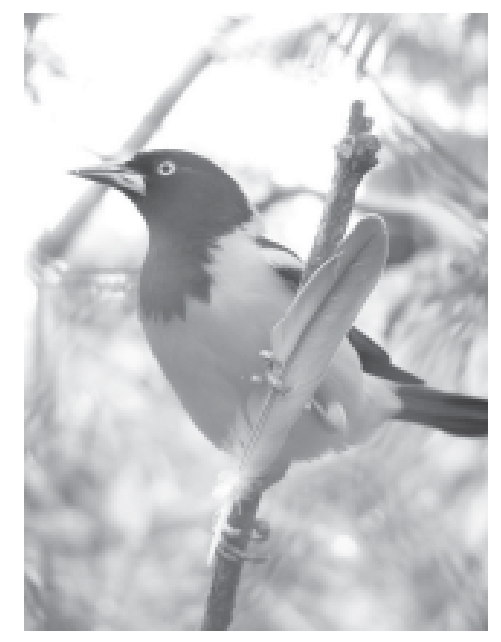

Figura 1. Fotografia de um corrupião segurando uma pena em uma das patas.

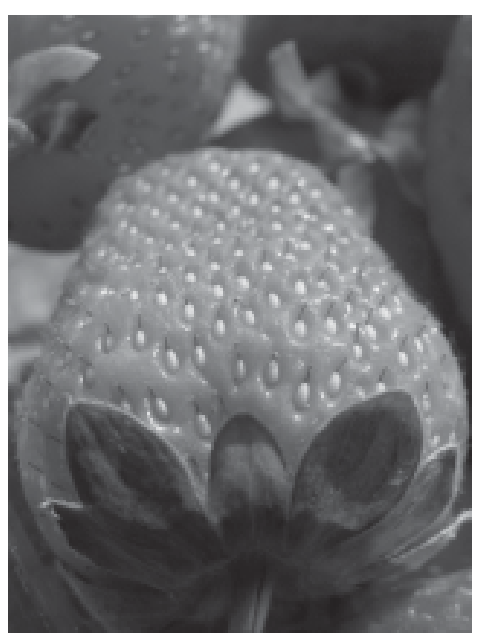

Figura 2. Fotografia de um morango.

No início, ao primeiro olhar, muitos comentam que ficam "com água na boca" e, no momento seguinte, falam que conseguem ver muito bem os detalhes. Mais uma vez, o objetivo foi alcançado e, a partir disso, podem-se introduzir alguns conceitos, como o de fruto composto, explicando que cada uma das partes em amarelo é um fruto e que, na verdade, o morango não é um fruto simples, e sim composto; é possível, ainda, explicar sobre a utilização de agrotóxicos, já que o morango é uma das frutas em que os defensivos agrícolas são muito utilizados.

Observando a reação das pessoas comentando fotografias de revistas, calendários e outras mídias, pude perceber que sempre questionavam algo ou comentavam sobre a exube- 
Borges, M. D.; Aranha, J. M.; Sabino, J.

rância de um animal ou paisagem. A partir dessa sensibilização e curiosidade frente a fotografias da natureza surgiu a ideia de introduzi-las como instrumento para a educação ambiental.

Os diversos meios de comunicação e informação jornalística, publicitária ou cultural que nos envolvem e fascinam, são essencialmente fotográficos, seja na forma de imagens estáticas ou dinâmicas. A fotografia, impressa, exposta ou projetada, sempre está presente. Sem dúvida, a fotografia integrou-se definitivamente em várias áreas das atividades humanas, proporcionando processos criativos na busca de novos patamares do conhecimento, em todas suas formas e níveis. Ao fornecer um sem número de possibilidades plásticas e/ou gráficas, a fotografia provoca dúvidas, gera questionamentos e sugere soluções na busca de resultados, tanto para artistas quanto para cientistas, e também ao homem comum, em sua contemplação desinteressada (ou não) do mundo que o cerca.

Os sinais de vida congelados numa fotografia são índices do mundo do passado que se busca compreender e podem se transformar em testemunho de uma realidade a ser construída. (LEITE, 1993, p. 23)

Com essa citação de Leite (1993), podemos perceber as várias facetas que tem a fotografia, pois pode tanto ser uma "testemunha" do que já passou quanto servir de base para um novo pensamento. Ora, se a educação ambiental surge para favorecer a aquisição de conhecimentos, valores e comportamentos; propiciar uma percepção de Meio Ambiente como interação de vários aspectos; contribuir para formação de uma consciência sobre a preservação da qualidade do Ambiente, entre outros aspectos, tudo isso significa uma realidade a ser construída por um indivíduo ou grupo. A Fotografia entra não somente como um meio de informações e documentações visuais - como ocorre geralmente com o uso desta linguagem mas também oportuniza a aplicação dessas imagens como forma de mudança de comportamentos e atitudes em relação aos problemas ambientais e ecológicos. A educação ambiental, por meio da percepção ambiental, promove uma sensibilização e tomada de consciência do ser humano para as questões socioambientais (SABINO, 2009).

De acordo com Gomes (1996), ao registrar a experiência a imagem fotográfica pode provocar novas percepções, produzir a subjetividade inerente ao ato de olhar e imortalizar o fato e o espaço captados, contextualizando-os. Ainda segundo Gomes (1996), com a fotografia tem-se uma oportunidade de trabalhar essa percepção ambiental por meio da sensibilização; ou, ainda, utilizar uma imagem de anos passados e outra recente, de um local, para demonstrar a devastação, por exemplo. Também esse autor diz que fotografar é uma forma de expressão, o "congelamento" de uma situação e seu espaço físico inserido na subjetividade de um realismo virtual.

Para Ferrara (1999), a fotografia por meio da máquina fotográfica pode ser um instrumento eficaz detonador da capacidade perceptiva, ou indicador do estágio dessa percepção. Ou seja, uma imagem, se não é capaz de sensibilizar, pode, ao menos, demonstrar quanto o observador conhece sobre o assunto em questão, pois se uma fotografia não causa nenhum tipo de "agitação", isso pode levar a crer que a percepção ambiental daquele indivíduo é baixa. Segundo Franscatel (1993), deu-se uma ênfase exagerada ao texto escrito na formação geral das gerações recentes, o que nos levou a uma crise, pois o homem não só vive pelas palavras, mas também pelos olhos e ouvidos. Nós dependemos da visão para grande parte da comuni- 
A fotografia de natureza como instrumento ...

cação humana. A visão evolui como sentido dominante nos primatas (BERNE e LEVY, 1998). A visão tem essa importância, pois oferece diversas informações que nenhum outro tipo de recepção e transmissão de informações oferece. As estruturas fotossintetizantes, que recebem as informações luminosas e transmitem para o sistema nervoso central, fornecem percepção de claro/escuro, direção, formação de imagem e cor.

Nosso foco neste trabalho será a avaliação da eficiência na utilização da fotografia da natureza na educação ambiental em escolas do Ensino Fundamental e Educação de Jovens e Adultos (EJA) de escolas públicas. A preocupação com a conservação do Mundo Natural é cada dia mais constante, e aspectos relacionados a Ecologia e problemáticas ambientais estão sendo incorporados continuamente ao currículo destes níveis de Ensino. A fotografia possibilita "ver sem ter estado lá" o que é de fundamental importância nesse tipo de atividade, pois com isso pode-se despertar o aluno para a curiosidade pelo novo. Um outro lado é a utilização de imagens para demonstrar algum processo ecológico, estimulando a busca pelas causas, ou, ainda, ao expor imagens de situação de natureza degradada, estimular a reflexão e crítica para os riscos e danos ambientais. Além disso, a fotografia é de extrema utilidade quando em conjunto com a descrição de algum animal, planta ou bioma - uma descrição de uma ave brasileira, por exemplo, se acompanhada de uma fotografia, facilita o entendimento de vários aspectos como da morfologia e comportamento daquele animal.

\section{Objetivos}

Analisar como a fotografia instrumentaliza a educação ambiental e pode contribuir para o aprendizado de alunos do Ensino Fundamental e Médio e, por meio dos métodos a seguir descritos, verificar ainda se a fotografia promove e incentiva a educação ambiental com esses alunos.

\section{Material e métodos}

O trabalho foi realizado por meio de apresentação de palestra e posterior avaliação da aprendizagem de alunos nas faixas de idade de 12 a 15 anos e adultos, todos de Escolas do Ensino Fundamental, Médio e Educação de Jovens e Adultos (EJA) da região de Curitiba, Paraná, e Bombinhas, Santa Catarina.

\section{Aulas}

Foram ministradas aulas/palestras baseadas em um texto (Anexo 1) sobre o tema " $A$ importância da natureza e o impacto causado pelo homem". Os recursos utilizados foram aulas expositivas dialogadas com apresentação em multimídia utilizando-se fartamente fotografias. Estas aulas foram realizadas em duas turmas de cada série nas diferentes escolas. Ao todo, foram ministradas 12 palestras em 12 turmas diferentes. Em metade das turmas, utilizaram-se fotografias para exemplificar, ilustrar etc.; em seguida, foi aplicada uma avaliação (Anexo 2a) com questões sobre o tema da aula na qual foi observado o aprendizado e, ainda, questões para 
Borges, M. D.; Aranha, J. M.; Sabino, J.

informar se os alunos acharam que a utilização de fotografias como instrumento auxiliou e se gostariam que fossem sempre utilizadas nas aulas de Ciências/Biologia. Na outra turma, não houve o uso de imagens no decorrer da palestra, as quais foram mostradas após a avaliação (Anexo 2b). Ao final da aula (sem as imagens), foi entregue uma avaliação com questões sobre o assunto tratado na aula e, após isso, as fotografias foram utilizadas como instrumento. Após o uso das imagens, foi entregue um segundo questionário (Anexo 2c) para verificar se os alunos gostariam que as fotografias tivessem sido utilizadas durante a aula, e não só ao final, e se gostariam que fotografias fossem utilizadas sempre em suas aulas de Ciências/Biologia.

\section{Análise dos dados}

Os resultados foram analisados pelo número de acertos que os alunos tiveram para o conjunto de questões apresentadas e, nas questões 1, 2 e 3, individualmente. Além disso, foi também analisado, comparativamente, o desempenho de alunos em diferentes faixas etárias (12 a 15 e adultos). Os resultados foram testados quanto à significância com um teste de $\chi^{2}$ considerando o nível de significância 0,05 .

\section{Resultados}

Os resultados das respostas das questões apresentadas aos alunos estão na Tabela 1. Observa-se que houve elevado nível de acerto nas três questões, mas aumento no acerto entre os alunos que tiveram a palestra com as fotografias.

Tabela 1. Número e porcentagem de acerto nas respostas às questões apresentadas aos alunos após palestras com e sem apresentação das fotografias.

\section{Questões}

1. Se as árvores de uma floresta forem derrubadas para a construção de uma casa, isso afetaria animais como as abelhas?

2. O homem não é o principal causador de danos ao ambiente, como o aumento do efeito estufa e destruição da camada de ozônio?

3. A natureza nos fornece elementos para produção de: roupas, combustíveis e medicamentos, por exemplo?

4. Você achou que a utilização das fotografias ajudou a explicação/Você acha que, se as fotografias tivessem sido mostradas durante a palestra, isso teria ajudado a explicação?

5. Você gostaria que fotografias fossem utilizadas sempre na sua aula de Ciências/Biologia?

$\frac{\operatorname{Sim}}{143 \quad 100 \%}$\begin{tabular}{llllll}
0 & $0 \%$ & & Não & & \multicolumn{2}{c}{ Sim } & & \multicolumn{2}{c}{ Não } \\
\hline & 135 & $100 \%$ & & 0 & $0 \%$
\end{tabular}

\begin{tabular}{|c|c|c|c|}
\hline \multicolumn{2}{|c|}{$\begin{array}{c}\text { Com fotografias } \\
\qquad N=143\end{array}$} & \multicolumn{2}{|c|}{$\begin{array}{c}\text { Sem fotografias } \\
\qquad N=135\end{array}$} \\
\hline Sim & Não & Sim & Não \\
\hline $97,2 \%$ & $4 \quad 2,8 \%$ & $11182,2 \%$ & $24 \quad 17,8 \%$ \\
\hline
\end{tabular}

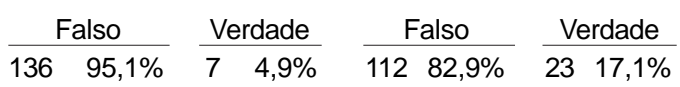

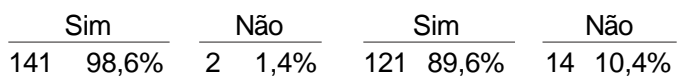

\begin{tabular}{|c|c|c|c|}
\hline Ajuda & Atrapalha & Sim & Não \\
\hline $99,3 \%$ & $1 \quad 0,7 \%$ & $12693,3 \%$ & $9 \quad 6,7 \%$ \\
\hline
\end{tabular}

Ciência §̊̊ Educação, v. 16, n. 1, p. 149-161, 2010 
A fotografia de natureza como instrumento ...

A Figura 3 mostra a distribuição das frequências percentuais das respostas dos alunos mostrando que, exceto na pergunta 5 , todas as porcentagens foram maiores entre os alunos que tiveram palestra com as fotos.

A análise estatística das respostas mostra que a diferença na frequência de acertos para o conjunto das questões 1 a 3 foi significativa $\left(\chi^{2}=37,295 ; \alpha=0,05\right)$, assim como individualmente para as questões $1\left(\chi^{2}=17,204 ; \alpha=0,05\right), 2\left(\chi^{2}=10,633 ; \alpha=0,05\right), 3\left(\chi^{2}=10,306\right.$; $\alpha=0,05)$, e $4(\chi=7,128 ; \alpha=0,05)$.

$\mathrm{Na}$ questão 5, questionados quanto ao uso de fotografias em aulas de Ciências/ Biologia, 100\% dos alunos gostariam que estivessem sempre presentes em suas aulas.

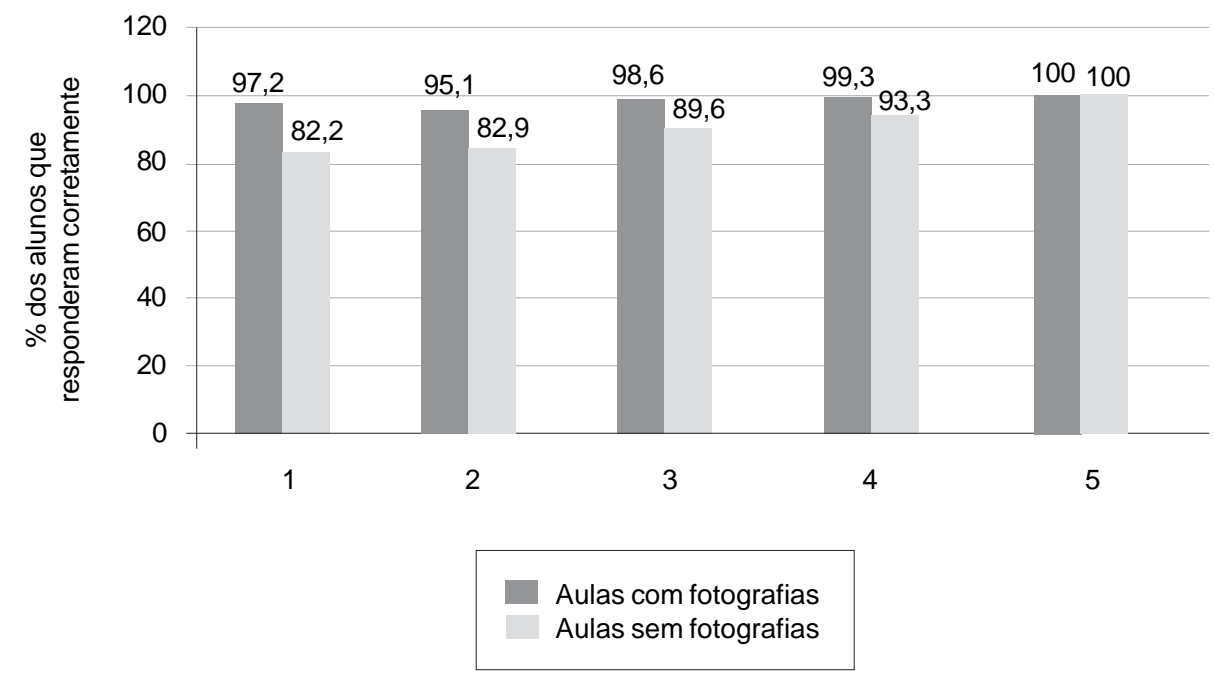

Figura 3. Frequência de acertos de cada questão apresentada nas aulas com fotografias e sem fotografias.

O número de acertos nas respostas das questões 1, 2 e 3 dadas pelos alunos de EJA (Adultos) são semelhantes ao número de acertos das mesmas questões dadas pelos alunos de $7^{\mathrm{a}}$ e $8^{\mathrm{a}}$ séries (Tabela 2 e Figura 4) nas aulas em que as fotografias foram utilizadas. A análise estatística confirma $\left(\chi^{2}=0,1607\right)$ que não há diferença significativa entre o número de erros e acertos entre os alunos de EJA (adultos) e $7^{\mathrm{a}}$ e $8^{\mathrm{a}}$ séries.

Tabela 2. Número de acertos e erros nas respostas às questões apresentadas aos alunos do EJA e das $7^{\mathrm{a}}$ e $8^{\mathrm{a}}$ séries.

\begin{tabular}{ccc}
\hline Questões & $\begin{array}{c}\text { EJA } \\
N=141\end{array}$ & $\begin{array}{c}7^{\mathbf{a}} \text { e } \mathbf{8}^{\mathrm{a}} \text { séries } \\
\mathrm{N}=137\end{array}$ \\
\hline Acertos & 205 & 211 \\
Erros & 8 & 10 \\
\hline
\end{tabular}


Borges, M. D.; Aranha, J. M.; Sabino, J.

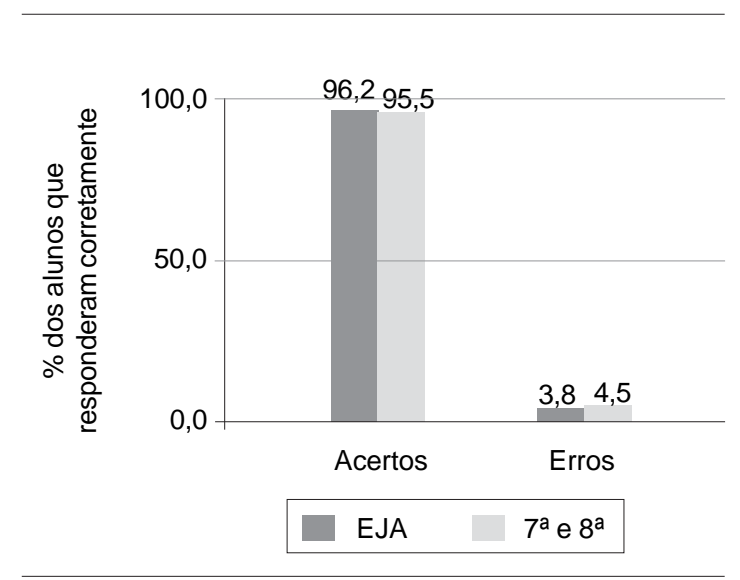

Figura 4. Frequência de acertos de cada questão apresentada aos alunos do EJA e das $7^{\mathrm{a}}$ e $8^{\mathrm{a}}$ séries.

\section{Discussão}

O método utilizado neste estudo - observando os acertos em questões relacionadas com o tema discutido na palestra e sobre a utilização das fotografias nas aulas - se mostrou eficiente, pois permitiu verificar se o uso da fotografia auxiliou ou não no aprendizado dos alunos. Este método foi escolhido, pois, além de ter se mostrado eficaz, é uma avaliação rápida, visto que o tempo para aplicá-la ao final da palestra era curto. Na bibliografia não foi encontrada nenhuma abordagem semelhante que utilizasse esse tipo de avaliação, até porque trabalhos semelhantes a este são muito escassos.

Com base nos resultados, verificou-se a colaboração da fotografia no processo de aprendizado, ou seja, sua utilização como instrumento na educação ambiental teve grande influência nas turmas, pois aquelas onde as fotografias foram utilizadas como recurso apresentaram um melhor desempenho nas questões avaliativas. Foi levado aos alunos algo diferente, que chamou sua atenção e, então, se demonstraram problemas ambientais e a importância da Natureza. A partir da visualização das fotografias é que o tema foi discorrido e, como citado por Douglas (2000) e Berne e Levy (1998), o que pode ter sido um dos pontos-chave é que a visão é o sentido mais evoluído em nós, humanos, que nos guia em vários aspectos das nossas vidas. Além disso, devemos lembrar que a fotografia é um instrumento de sensibilização que pode provocar novas percepções e produzir a subjetividade inerente ao ato de olhar (GOMES, 1996), e, ainda, pode ser responsável pela capacidade de perceber, como diz Ferrara (1999). Por esta e outras características citadas, a fotografia auxiliou aumentando o aprendizado das turmas.

Na questão 4 questionou-se aos alunos se a fotografia havia ajudado ou não na aprendizagem (para as turmas onde as imagens foram utilizadas) ou se as fotografias deveriam ter sido utilizadas durante a palestra (para aquelas turmas nas quais as imagens foram mostradas após). Houve uma diferença significativa entre as respostas das turmas destas duas categorias, com isso pode-se inferir que a demonstração das fotografias apenas ao final da palestra, por- 
A fotografia de natureza como instrumento ...

tanto após a explicação, não foi suficiente para o aprendizado. Este instrumento deve ser utilizado durante as aulas para dar explicações, exemplificar, provocar dúvidas e questionamentos, sensibilizar, e para qualquer outra finalidade que o educador ache conveniente, pois a fotografia é um recurso que pode ser inserido no dia-a-dia escolar de diversas maneiras, além de ser extremamente versátil, podendo moldar-se às necessidades de cada professor.

A fotografia da natureza mostrou-se eficaz tanto para crianças (sétima e oitava séries) quanto para adultos (EJA, terceiro e quarto ciclos e quarto segmento). Isso é uma ótima afirmação, pois isso demonstra que este instrumento pode ser utilizado com eficácia para diferentes faixas etárias. Tanto crianças quanto adultos foram sensibilizados e tiveram sua atenção voltada para as fotografias, mostrando a versatilidade do recurso também em diferentes níveis de ensino, pois os alunos de EJA que participaram estão no terceiro e quarto ciclos, que equivalem à quinta, sexta, sétima e oitava séries, além daqueles do quarto segmento, que corresponde ao Ensino Médio.

Este trabalho abre as portas para educadores de outras áreas que queiram também beneficiar-se deste recurso que se mostrou tão eficaz. Uma variável que pode ser aplicada é fazer com que os próprios alunos fotografem, o que levaria a uma percepção ambiental antes mesmo da fotografa propriamente dita, mas também a uma percepção do ambiente e seus componentes, para então registrá-los por meio das lentes da máquina fotográfica.

O presente trabalho demonstrou que o papel da fotografia, não só na transferência de informação como também na sensibilização e transformação do educando, é de grande eficiência, independente da faixa de idade e do nível de aprendizagem. Trata-se, portanto, de um instrumento cada vez mais barato e de grande impacto no observador. Desta forma, o uso adequado da fotografia pode representar um grande passo na formação de cidadãos mais conscientes e com percepção do ambiente que os cerca.

\section{Referências}

BERNE, R. M.; LEVY, M. N. Fisiologia. 4. ed. Rio de Janeiro: Guanabara Koogan, 1998.

BRASIL. Lei Federal 9.795, de 27 de abril de 1999. Dispõe sobre a educação ambiental, institui a Política Nacional de Educação Ambiental e dá outras providências. Diário Oficial da República Federativa do Brasil, Brasília, DF, 28 de abril 1999.

DOUGLAS, C. R. R. Tratado de Fisiologia aplicado às Ciências da Saúde. 4. ed. São Paulo: Robe, 2000.

FERRARA, L. D. Olhar periférico: informação, linguagem, percepção ambiental. 1. ed. São Paulo: Edusp, 1999. 
Borges, M. D.; Aranha, J. M.; Sabino, J.

FRANCASTEL, P. A realidade figurativa. 1. ed. São Paulo: Perspectiva/USP, 1993.

GOMES, P. Da escrita a imagem: da fotografia à subjetividade. 1996. 62f. Dissertação (Mestrado em Psicologia) - Instituto de Psicologia, Universidade Federal do Rio Grande do Sul, Porto Alegre, 1996.

LEITE, M. M. Retratos de família: leitura da fotografia histórica. 1. ed. São Paulo: EDUSP, 1993.

SABINO, J. Técnica e ética da fotografia do comportamento animal: dos pioneiros à era digital. Oecologia Brasiliensis, v. 13, n. 1, p. 209-221, 2009.

SAUVÉ, L. Educação ambiental: possibilidades e limitações. Educação e Pesquisa, São Paulo, v. 31, n. 2, p. 317-322, 2005.

SPENCER, D. Color Photography in Practice. 2. ed. Londres: Iliffe \& Sons, 1980. 
A fotografia de natureza como instrumento ...

Anexo 1. Texto no qual se baseia a palestra.

A importância da natureza e o impacto causado pelo homem

Por que conservar o Ambiente? Por que simplesmente não deixamos uma espécie ser extinta? Vamos pensar em uma floresta... Ela se mantém sozinha? Ou seja, é necessário que plantemos árvores, reguemo-las, etc.? Não, ela se mantém sozinha e, por isso, dizemos que está em equilíbrio; os animais e plantas vivem em equilíbrio e não precisam do homem para sobreviver e se manterem.

Certas aves dessa floresta, como os tucanos e araçaris, alimentam-se dos frutos de determinadas árvores. Com isso, estas aves ajudam a dispersar sementes e, consequentemente, originar novas árvores. E se uma família de humanos quiser morar nessa floresta? O que vai acontecer? Vai ser preciso que essas árvores sejam derrubadas para a construção de uma casa, desta maneira, os pássaros ficarão sem alimentos e não mais poderão ajudar no nascimento de novas árvores.

Vamos a outro exemplo. Vocês sabem do que as abelhas se alimentam? Do néctar das flores. Estas flores estão em árvores, certo? E se alguém quiser cortar essas árvores para construir os móveis de sua casa? As abelhas vão ficar sem alimentos. E vocês sabiam, também, que as abelhas ajudam na dispersão do pólen? As abelhas e outros insetos, quando vão se alimentar do néctar das flores, carregam em seu corpo o pólen e, quando vão se alimentar de outra flor, auxiliam na polinização. Polinização é quando o pólen - parte masculina da flor - se encontra com o ovário - parte feminina da flor -e, desta junção, forma-se um fruto que contém sementes. Estas sementes, por sua vez, quando caem no solo, originam uma nova árvore. Então, se o alimento da abelha que está nas flores for retirado pelo corte das árvores, as abelhas morrerão e a perpetuação desta árvore vai ser prejudicada.

Biodiversidade

O que é a biodiversidade? É a variedade de vida no planeta Terra, a variedade de espécies da flora, da fauna e de microrganismos, variedade de hábitats e ecossistemas.

E por que essa biodiversidade é tão importante? Pois é responsável pelo equilíbrio e estabilidade dos ecossistemas, como pudemos perceber nos exemplos citados anteriormente. Além disso, é dela que retiramos muitos de nossos alimentos (pedir para que os alunos deem alguns exemplos de alimentos que consomem no dia-a-dia), remédios, o ar que respiramos e a água que bebemos, ou seja, sem essa diversidade biológica não seria possível a vida do homem na Terra.

Os nossos alimentos e a água que bebemos vêm de onde? Quem gosta de frutas? De onde elas vêm, do mercado? Não, elas estão em árvores que estão plantadas em um solo. As frutas, verduras, trigo, arroz, etc. precisam de um solo adequado para que tenham boas condições de crescimento e possamos nos alimentar. $\mathrm{E}$ se, ao lado do pomar ou da horta, existir uma fábrica ou algumas casas que despejem seu lixo diretamente no solo? Toda a plantação pode ser contaminada e quem ingerir estes produtos também pode ter muitos problemas. Quanto tempo vocês acham que uma garrafa pet leva para se decompor no ambiente? Primeiro vou explicar sucintamente o que é decompor. Há micro-organismos - fungos e bactérias além de algumas larvas - que se alimentam de matéria orgânica. Imaginem se todas as folhas que caem de uma árvore se acumulassem no solo! Esses micro-organismos, chamados decompositores, alimentam-se desses restos de plantas e animais, e podemos dizer, então, que eles fazem a limpeza do nosso planeta. Eles se alimentam de MATÉRIA ORGÂNICA. Uma garrafa pet ou uma sacola plástica é matéria orgânica? Não! Ela leva de 200 a 400 anos para ser degradada pelo ambiente. Como eu já mencionei, o Ambiente está em equilíbrio, só que este equilíbrio não envolve o lixo.

Vamos imaginar que estamos passeando e encontramos um rio. Alguém beberia água desse rio? Por quê? Porque ela pode estar suja? Será que isso sempre foi assim? Alem de saciar nossa sede, para que mais serve a água? Aágua, tanto doce como salgada, é o hábitat de muitos organismos, desde vegetais e animais microscópicos até grande mamíferos. Retomando nosso exemplo, o que pode contaminar as águas? Lixo diretamente ou indiretamente pelo chorume (é o líquido resultante da decomposição da matéria orgânica), produtos químicos, esgoto não tratado, agrotóxicos, entre outros (explicar cada um). E de onde vêm estes contaminantes? O homem que os produz e lança nas águas. Se o homem não existisse ou tivesse consciência disso tudo que foi dito, nós não precisaríamos nos preocupar em beber uma água de um rio qualquer, pois ela seria quase sempre potável.

O que todos nós estamos fazendo agora e precisamos disso para sobreviver? Respirando! Nós e todos os outros animais, plantas e seres vivos, cada um da sua maneira. A poluição do ar tem muitas origens: os carros, os caminhões, as indústrias, etc., são fontes poluidoras. Quando respiramos ar poluído, partículas nocivas 
Borges, M. D.; Aranha, J. M.; Sabino, J.

podem se depositar no pulmão e causar doenças além de atingirem outros locais do corpo. E com os outros animais acontece o mesmo, assim como com as plantas, pois todos os seres vivos precisam do ar para sobreviver. Todos os seres vivos no mundo respiram o mesmo ar? Sim, pois uma única atmosfera nos rodeia e, se alguma ação negativa é realizada em um local do mundo, podemos sentir os efeitos em áreas bem distantes.

Como exemplos dos danos que a poluição do ar pode causar, podemos citar a destruição da camada de ozônio e o aumento do efeito estufa:

Efeito estufa é um fenômeno natural sem o qual não sobreviveríamos, pois ele mantém uma temperatura tal que todos os seres vivos do planeta suportam. O problema, amplamente discutido atualmente, é o aumento desse efeito estufa, o que desestabilizaria o "equilíbrio" na Terra e originaria o aquecimento global. Explicando sucintamente, a atmosfera é composta de gases que absorvem radiação infravermelha (calor) transmitida pela Terra e radiam uma parte dessa energia de volta ao espaço. A poluição dos últimos duzentos anos tornou mais espessa a camada de gases existentes na atmosfera e essa camada retém a radiação infravermelha (calor) emitida pela superfície do planeta dando o efeito de "estufa" (ilustração tipo infográfico). Alguns dos efeitos são: O aumento da temperatura da água, o que leva ao derretimento das calotas polares e de geleiras que eleva o nível das águas dos oceanos e dos lagos, submergindo ilhas e amplas áreas litorâneas densamente povoadas. O superaquecimento das regiões tropicais e subtropicais contribui para intensificar o processo de desertificação e de proliferação de insetos nocivos à saúde humana e animal. A destruição de habitats naturais provoca o desaparecimento de espécies vegetais e animais. Multiplicam-se as secas, inundações e furacões.

A diminuição na camada de Ozônio: Esta camada filtra os raios ultravioleta vindos do Sol e, assim, impede que essa radiação chegue de forma nociva à superfície. A diminuição da camada de ozônio está ocorrendo devido ao aumento da concentração dos gases CFC (cloro-flúor-carbono) presentes no aerossol, em fluidos de refrigeração etc. O Cloro do CFC reage com o Ozônio formando o Monóxido de Cloro, ou seja, diminui a quantidade de Ozônio e, consequentemente, a penetração de raios UV, altamente nocivos em grande quantidade, podendo causar catarata e câncer de pele no homem e diversos problemas em outros animais, com destaque para aumento da taxa de mutação genética.

A natureza é uma fonte riquíssima de vários recursos, vocês podem me dar algum exemplo?

Medicamentos: Grande parte é composta por algo que vem da natureza ou, ao menos, teve um modelo baseado nela.

Combustíveis: Os combustíveis mais utilizados hoje - álcool, gasolina, óleo diesel e GNV - são formados a partir de elementos da natureza: petróleo e cana-de-açúcar. Aqui enfrentamos outro problema - o dos recursos renováveis e não-renováveis. Gasolina e óleo diesel são fabricados a partir do petróleo, que é um recurso nãorenovável, ou seja, ele vai acabar, não temos como renovar o "estoque", além de sua conversão para combustível ser altamente poluente (obs.: é com petróleo que se fabrica plástico). Já o álcool é fabricado a partir da cana-deaçúcar, um recurso renovável, pois podemos plantar a cana, colher e replantar (falar sobre o problema das monoculturas?).

Fibras: Todos estamos vestindo fibras! É com elas que fabricamos tecidos. Também, todos estamos escrevendo em fibras, pois o papel é feito de fibras de celulose. Podem ser naturais - são as fibras retiradas prontas da natureza, sendo as mais comuns o algodão, a lã, a seda e o linho; ou artificiais - que são produzidas pelo homem, porém utilizando, como matéria-prima, produtos da natureza, como a celulose. As mais comumente utilizadas são a viscose, o Modal etc.

Polinização: É o encontro da parte masculina com a feminina de uma planta, produzindo sementes, ou seja, é assim que há a proliferação de uma espécie vegetal. Quem faz essa polinização? O vento, a água, insetos, e alguns vertebrados como morcegos ou aves (explicar cada um). Essa é uma das partes que sustenta o equilíbrio de Ambiente do qual estamos falando.

A natureza ainda auxilia no controle de doenças, renova a fertilidade do solo, além de oferecer benefícios culturais.

Retomando a questão inicial: Por que conservar o ambiente? Pois a natureza está em equilíbrio e oferece tudo o que os seres vivos, inclusive o homem, necessitam para sobreviver. A Terra já sente os efeitos da degradação ambiental há muito tempo e, se não fizermos algo para contermos esta destruição causada pelo homem, a vida vai se tornar insustentável. 
A fotografia de natureza como instrumento ...

Anexo 2. Questões entregues aos alunos.

2.a - Questões respondidas pelos alunos das turmas nas quais foram utilizadas fotografias:

1 - Se árvores de uma floresta forem derrubadas para a construção de uma casa, isso afetaria animais como as abelhas?

( ) SIM ( ) NÃO

2 - O homem não é o principal causador de danos ao ambiente, como o aumento de efeito estufa e destruição na camada de ozônio. Isto é:

( ) VERDADEIRO ( ) FALSO

3 - A natureza nos fornece elementos para produção de: roupas, combustíveis e medicamentos?

( ) SIM ( ) NÃO

4 - Você achou que utilização das fotografias:

( ) ajudou a explicação ( ) atrapalhou a explicação

5 - Você gostaria que fotografias fossem utilizadas sempre nas suas aulas de Ciências/Biologia?

( ) SIM ( ) NÃO

2.b - Questões respondidas pelos alunos das turmas nas quais as fotografias foram utilizadas após este:

1 - Se árvores de uma floresta forem derrubadas para a construção de uma casa, isso afetaria animais como as abelhas?

( ) $\operatorname{SIM~(~)~NÃO~}$

2 - O homem não é o principal causador de danos ao ambiente, como o aumento de efeito estufa e destruição na camada de ozônio. Isto é:

( ) VERDADEIRO ( ) FALSO

3 - A natureza nos fornece elementos para produção de: roupas, combustíveis e medicamentos? ( ) SIM ( ) NÃO

2.c - Questões respondidas pelos alunos das turmas onde as fotografias não foram utilizadas durante a palestra, apenas após. Seguido da apresentação das imagens, estas questões foram entregues:

4 - Você acha que, se as fotografias tivessem sido mostradas durante a palestra, isso teria ajudado a explicação?

( ) SIM ( )NÃO

5 - Você gostaria que fotografias fossem utilizadas sempre nas suas aulas de Ciências/Biologia?

( ) $\operatorname{SIM}$ ( ) NÃO 